\title{
Fenologia reprodutiva e biologia da polinização de Canavalia brasiliensis Mart. ex Benth (Fabaceae)
}

\author{
Roberta Sales Guedes ${ }^{1 *}$ \\ Zelma Glebya Maciel Quirino \\ Edilma Pereira Gonçalves ${ }^{3}$ \\ 'Departamento de Fitotecnia, Centro de Ciências Agrárias \\ Universidade Federal de Paraíba, CEP 58.397-000, Areia - PB, Brasil \\ ${ }^{2}$ Universidade Federal da Paraíba, Campus IV - Litoral Norte \\ ${ }^{3}$ Universidade Federal Rural de Pernambuco, Garanhuns - PE, Brasil \\ * Autor para correspondência \\ roberta_biologa09@yahoo.com.br
}

Submetido em 08/05/2008

Aceito para publicação em 27/09/2008

\section{Resumo}

A fenologia reprodutiva e a biologia da polinização foram estudadas em plantas de Canavalia brasiliensis Mart. ex Benth (Fabaceae). A área de ocorrência natural localiza-se no município de em Pocinhos - PB. O trabalho teve como objetivo estudar a fenologia e biologia da polinização de C. brasiliensis. Quinze indivíduos foram marcados e acompanhados quinzenalmente para as observações dos estudos fenológicos. Para o estudo da morfologia e biologia florais, flores e inflorescências foram marcadas e acompanhadas até a formação dos frutos. Os visitantes florais foram observados ao longo do período do experimento, anotando-se freqüência, horário e comportamento de suas visitas. Canavalia brasiliensis demonstrou padrão de floração anual, contínua, de longa duração com períodos de maior atividade fenológica de floração na estação seca. As inflorescências são do tipo paniculada, com flores cujos atributos florais estão relacionados à síndrome da melitofilia. A antese é diurna, com início às 05 h00. Há néctar desde a fase de pré-antese, com concentração de açúcares em torno de 44-60\%. Os visitantes florais observados foram abelhas (Xylocopa frontalis, X. suspecta e X. sp. Apis mellifera e Centris similis) e pássaros (Phaethornis ruber, Chlorostilbon aureoventris, Eupetomena macroura e Coereba flaveola). Xylocopa frontalis atuou como polinizadora efetiva, enquanto que os pássaros restringem-se a pilhar o néctar.

Unitermos: caatinga, biologia floral, polinizadores, visitantes florais, fenologia

\section{Abstract}

Reproductive phenology and pollination biology of Canavalia brasiliensis Mart. ex Benth (Fabaceae). This work studied the phenology and biology of the pollination of $C$. brasiliensis in an area of its natural occurrence (Pocinhos - PB). Fifteen plants were marked and observed every two weeks for the study of phenology. For the study of floral biology and morphology, flowers and inflorescences were marked and observed until fruit appeared. Visitors to flowers were observed throughout the experiment, and the frequency, time and behavior of their visits was registered. Canavalia brasiliensis demonstrated a pattern of annual flowering which was continuous, of long duration, with periods of greater flowering activity in the dry season. The inflorescence is of the paniculatum type, with flowers whose attributes are related to the syndrome of melittophily. Anthesis occurs 
during the day, beginning at $05 \mathrm{~h} 00$. Nectar is produced from the phase of pre-anthesis, with a concentration of sugars around 44-60\%. Visits by bees (Xylocopa frontalis, X. suspecta and X. sp., Apis mellifera and Centris similis) and birds (Phaethornis ruber, Chlorostilbon aureoventris, Eupetomena macroura and Coereba flaveola) were observed. Xylocopa frontalis acted as an effective pollinator.

Key words: caatinga, floral biology, pollinator, floral visitors, phenology

\section{Introdução}

A caatinga é um tipo vegetacional semi-árido exclusivo do Brasil, abrangendo aproximadamente $800.000 \mathrm{~km}^{2}$ (Ab'Saber, 1977). Embora constitua uma biota única no Brasil e no mundo, a caatinga vem sofrendo com a ação antrópica, a qual contribui para a perda da significativa biodiversidade desta região (Leal et al., 2003). Machado e Lopes (2003) mencionam que dentro da caatinga a família Fabaceae é o grupo mais representante, constituindo conforme Barroso et al. (1991) uma das maiores, dentre as Angiospermae, e que está amplamente distribuída em ambos os hemisférios, apresentando cerca de 482 gêneros e 12.000 espécies, dentre elas a Canavalia brasiliensis.

O desenvolvimento de pesquisas sobre os eventos fenológicos e os sistemas de polinização e reprodução das plantas é essencial para a melhor compreensão da biodiversidade da caatinga. Os conhecimentos biológicos a respeito $C$. brasiliensis são escassos, principalmente em relação aos aspectos da biologia floral e reprodutiva e ao comportamento fenológico.

Portanto, o detalhamento da caracterização fonológica e biologia da reprodução desta espécie apresentam-se com certa relevância, pois a sua importância tem sido ressaltada sob diversos aspectos: como um biossensor (Rover Júnior, 1995), na adubação verde (Carvalho e Sodré Filho, 2000), como agente de controle comportamental e/ou probiótico para colônias de saúva do nordeste (Isidro et al., 2001), como forrageira (Sampaio, 2002) e na medicina, sendo que de suas semente foram extraídas as lectinas ConA, as quais demonstraram uma ação na morte celular e/ou inibição de proliferação celular em linhagens tumorais (Pereira, 2005).

Os padrões fenológicos e biologia floral podem auxiliar na compreensão da dinâmica das comunidades e populações do ecossistema caatinga, subsidiando a implantação de programas de manejo e conservação
(Machado e Lopes, 2003). As relações entre as flores e seus polinizadores são comumente interpretadas como resultado de interações, nas quais as estruturas florais estão adaptadas para aperfeiçoar o transporte de pólen e mediar a ação dos vetores (Proctor et al., 1996).

De modo geral, as flores têm características que estão relacionadas a um determinado agente polinizador e estas constituem as síndromes de polinização. $\mathrm{O}$ entendimento do sistema reprodutivo é fundamental para a compreensão da biologia reprodutiva da espécie e base para desenvolvimento de programas de melhoramento genético (Wendt et al., 2001).

A fenologia das plantas pode ser influenciada por fatores próximos e fatores finais. Fatores próximos incluem precipitação, estresse hídrico, irradiação e fotoperíodo, enquanto fatores finais incluem a reprodução cruzada entre indivíduos e abundância de polinizadores, dispersores e predadores de sementes (Pedroni et al., 2002). O conhecimento adquirido nos estudos fenológicos tem implicações práticas importantes, incluindo a produtividade de culturas agroflorestais, controle de pragas, recuperação de áreas degradadas e manejo de unidades de conservação (Biondi et al., 2007). Além disso, segundo o autor gera subsídios para a organização de estratégias de coleta de sementes, otimizando o esforço e os recursos disponíveis.

Considerando que as espécies dos ambientes de caatinga possuem diferentes estratégias fenológicas que lhes permitem superar as diferentes condições ambientais, este estudo teve como objetivos: I) apresentar o comportamento fenológico vegetativo e reprodutivo; II) averiguar se os eventos fenológicos se correlacionam com a sazonalidade pluviométrica; III) cooperar para a ampliação do conhecimento biológico da espécie, tais como morfologia e biologia floral, síndrome de polinização e sistema reprodutivo. 


\section{Material e Métodos}

\section{Espécie estudada}

Canavalia brasiliensis Mart. ex Benth. é uma trepadeira pertencente a família Fabaceae, cujos indivíduos podem atingir de $0,5 \mathrm{~m}$ a $5 \mathrm{~m}$, dependendo do porte (arbustivo ou arbóreo) da espécie suporte. As raízes são amarelas; as folhas alternadas, trifolioladas; as flores apresentam coloração roxa e as pétalas bastante perfumadas e estão reunidas em inflorescências do tipo paniculada terminal, com escapo floral de coloração verde-arroxeada. É conhecida popularmente na região de estudo como feijão-de-porco, feijão bravo ou feijão bravo do Ceará. A espécie é utilizada como biossensor (Rover Júnior, 1995), no controle de saúvas (Isidro et al., 2001), na medicina (Pereira, 2005).

\section{Local de estudo}

A coleta de dados ocorreu no período de maio/2005 a novembro de 2006, no município de Pocinhos, Paraíba $\left(07^{\circ} 09,44^{\prime}\right.$ 'S e $\left.36^{\circ} 02,92^{\prime} \mathrm{W}\right)$, cuja vegetação predominante é do tipo caatinga arbustiva aberta, com muitas espécies caducifólias (Eiten, 1983). A região é caracterizada pela diversidade de microhabitats o que confere à região um mosaico de vegetação típica de Caatinga até formações vegetais específicas nas rochas e solos arenosos pobres. Nesta área C. brasiliensis é encontrada de maneira esparsa em áreas abertas e alteradas, geralmente próximos à rodovia. $\mathrm{O}$ tipo climático predominante é o BSh, segundo a classificação proposta por Köeppen, definido como Semi-árido quente com chuvas de verão (Lima e Heckendorff, 1985). As chuvas são irregulares, sendo a precipitação anual de $650,0 \mathrm{~mm}$, com a estação chuvosa ocorrendo entre os meses de março a junho (Moreira, 1997).

\section{Coleta dos dados}

O trabalho de campo foi realizado entre maio de 2005 e novembro de 2006, somando um ano e seis meses de observações. Foram selecionados, de forma aleatória, 15 indivíduos para a coleta de dados fenológicos e de biologia floral e cinco indivíduos para os estudos de biologia reprodutiva. Os indivíduos apresentavam altura média entre 1 e $2 \mathrm{~m}$, apresentando inflorescências com cerca de seis botões florais em pré-antese. $\mathrm{O}$ número amostral reduzido é justificado pelo fato da espécie ocorrer em populações pequenas e isoladas (Mendonça e Lins, 2000).

A morfologia floral foi estudada a partir de material fresco e fixado em FAA 50\%. Trinta botões florais de indivíduos distintos e em pré-antese foram selecionados aleatoriamente, marcados com linhas coloridas e acompanhados de forma não sistematizada a partir da abertura para o registro de informações como: início da antese, receptividade do estigma, duração e odor da flor, processo de senescência dos componentes florais bem como volume e concentração de néctar (Dafni, 1992). O início da antese foi caracterizado por uma pequena abertura no ápice da flor. A receptividade do estigma foi testada com peróxido de hidrogênio (Zeisler, 1938).

Estas observações foram realizadas diretamente no campo e complementadas através da análise fotografias realizadas no laboratório, com o auxílio microscópio esterioscópio. As estruturas florais foram medidas com o auxílio de paquímetro.

Para a avaliação do volume de néctar 30 flores selecionadas aleatoriamente e em processo de abertura foram previamente isoladas em sacos de organza de náilon e marcadas com linhas coloridas. Na manhã seguinte ao isolamento a quantidade de néctar foi tomada entre $6 \mathrm{~h} 00$ e $18 \mathrm{~h} 00$, sendo efetuada com auxílio de microseringas introduzidas na base da corola (Inouye et al., 1980). As medidas de concentração e volume de néctar foram realizadas em intervalos regulares de $3 \mathrm{~h}$, durante todo o período de produção de néctar. A concentração foi medida com refratômetro de mão para estimar a concentração do néctar coletado em "equivalentes de sacarose".

As observaçõs dos eventos fenológicos foram realizadas no período de setembro/05 e outubro/06, quando 15 indivíduos foram marcados aleatoriamente no campo e acompanhados quinzenalmente. Foram observadas as seguintes fenofases: floração (botões florais ou flores abertas) e frutificação (frutos iniciados, verdes ou maduros). No decorrer do estudo, 100 inflorescências foram marcadas com fitas coloridas, 
sendo registrados a presença e ausência de flores e frutos. O padrão de floração da espécie foi determinado de acordo com a classificação proposta por Newstrom et al. (1994).

Observações não sistematizadas dos visitantes florais foram realizadas durante todo o trabalho de campo, concomitantemente à coleta de dados fenológicos e aos experimentos de biologia floral e reprodutiva, no horário compreendido entre $05 \mathrm{~h} 00$ e $18 \mathrm{~h} 00$. Foram visitadas 15 plantas para registrar aspectos referentes ao horário, freqüência, duração e comportamento de visita, bem como local de contacto com pólen e estigma, sendo utilizado intervalos de $2 \mathrm{~h}$, em dias e horários alternados, totalizando $200 \mathrm{~h}$ de observação ao longo do período de estudo (maio de 2005 a novembro de 2006).

A freqüência de visitas consistiu em anotar cada vez que os visitantes chegavam nas inflorescências e visitavam as flores. Os beija-flores foram identificados através de fotografias, por comparação, usando-se bibliografia especializada (Grantsau, 1989). Os demais foram coletados com auxílio de rede entomológica e espécimes-testemunho depositados na coleção entomológica da Universidade Federal da Paraíba (UFPB).

Para determinação da estratégia reprodutiva da espécie, inflorescências de cinco indivíduos na área de estudo foram previamente isoladas, no dia anterior a antese das flores, utilizando-se sacos de organza de náilon. Foram utilizados 30 botões florais destas inflorescências, para os seguintes tratamentos: 1 - autopolinização espontânea (inflorescências de indivíduos distintos contendo botões florais em préantese foram ensacadas e não receberam tratamento posterior, para a verificação da formação de frutos); 2 - polinização cruzada (colocando-se no estigma pólen proveniente de flores de outros indivíduos distantes pelo menos 50m); 3 - apomixia (botões florais em pré-antese tiveram todas as anteras extraídas, sendo, posteriormente ensacados).

Além desses tratamentos foram feitas marcações em flores sem cobertura e sem tratamento para verificar o sucesso da polinização em condições naturais (controle), estando as flores expostas as visitas florais. Para estimar a eficiência do polinizador, os botões foram ensacados antes e após a fase de pré-antese e após receberem a primeira visita dos agentes polinizadores.

\section{Materiais botânicos}

Materiais botânicos, coletados na área de estudo, foram herborizados e depositados no Herbário da Universidade Federal da Paraíba (Lauro Pires Xavier/ JPB), sob o número de registro 3.512.

\section{Análise Estatística dos dados}

Os testes foram realizados através do programa Statistica 6.0. Inicialmente foi realizada uma análise da normalidade das fenofases estudadas através do teste de Shapiro-Wilk, visando classificá-las como eventos paramétricos ou não paramétricos. Posteriormente, foi feito o teste de correlação de Spearman para verificar a existência ou não de correlação entre estas fenofases e a precipitação da região no período de estudo.

\section{Resultados e Discussão}

\section{Características da espécie}

Canavalia brasiliensis é uma trepadeira que apresenta inflorescência paniculada terminal, com escapo floral de coloração verde-arroxeada, medindo de 15,5 a $60,4 \mathrm{~cm}$, zigomorfas, pedunculadas, periantadas, diclamídeas, hermafroditas e dispostas de forma alterna e presas às nodosidades da raque da inflorescência (Figura 1a). O número de botões florais varia entre $18-55$, sendo observados três botões a cada nó. Em cada inflorescência pode-se verificar entre 1-6 flores abertas por dia.

É comum na família Fabaceae a disponibilidade de muitas flores por inflorescências por dia (Franco, 1995). Este caráter mostra-se vantajoso para a espécie, visto que aumenta a atratividade do polinizador, uma vez que há aumento na disponibilidade de néctar (Kiill e Drumond, 2001). Kiill e Drumond (2001), ao estudarem Gliricidia sepium, verificaram a antese de 5 a 45 flores por dia em cada inflorescência.

O cálice apresenta coloração verde-arroxeada, sendo do tipo bilabiado e que se encontra inteiramente 
fechado no botão floral, sem delimitação de lobos, rompendo-se regularmente na antese. A corola apresenta coloração rosa, sendo zigomorfa, pentâmera e de prefloração embricada.

Nas flores da espécie, distinguem-se facilmente as pétalas estandarte, as alas e a carena ou quilha (Figura $1 \mathrm{~b}, \mathrm{c}, \mathrm{d})$, que constitui um dos tipos de corola mais evoluído entre as subfamílias de Faboideae (Barroso et al., 1991). Nesta espécie o estandarte tem a função de suporte para alguns visitantes coletarem o néctar/pólen. Kiill e Drumond (2001) estudando G. sepium e Agostini (2004) observando Mucuna sp., ambas Fabaceae, registraram a mesma função para o estandarte.

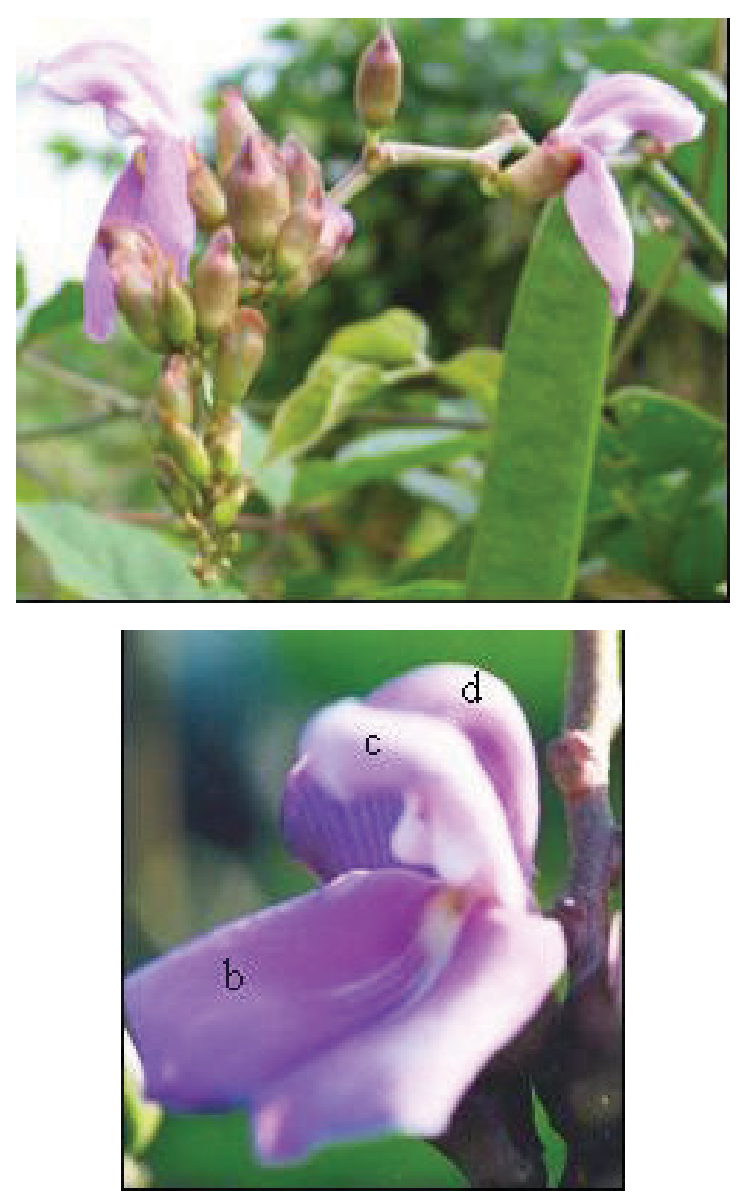

FIGURA 1: Inflorescência e em detalhe a flor de Canavalia brasiliensis Mart. ex Benth., em área de vegetação natural, Pocinhos - PB, no período de maio/2005 a novembro de 2006; a) Inflorescência de C. brasiliensis; b) estandarte; c) Alas; d) Quilha.

O androceu é diadelfo, onde há fusão de nove estames e o vexilar fica inteiramente livre, formando uma bainha, a qual abriga o estigma. Os estames são concrescidos e formam um único filete de coloração branca. As anteras são amarelas, livres, dorsifixas, bitecas, de deiscência longitudinal e pólen pulverulento.

O estigma é terminal e globoso de cor esverdeada, com estilete curvo e glabro também verde. $\mathrm{O}$ ovário é densamente piloso. Tais caracteres também são observados no gênero Dioclea (Barroso et al., 1991).

\section{Antese}

A antese é diurna e inicia com a abertura das flores por volta das 5 h00, com distensão lenta dos lobos da corola, ocasião em que as anteras iniciam a deiscência e permanecem inclusas na quilha. A antese é assincrônica, sendo que a maioria das flores abre por volta das $06 \mathrm{~h} 30 \mathrm{e}$ as demais flores só se encontram completamente abertas em torno das $08 \mathrm{~h} 00$, com os lobos da corola reflexos. O padrão de abertura floral observado em $C$. brasiliensis é semelhante ao citado por Kiill e Drumond (2001) para G. sepium (Fabaceae) caracterizando-se pela distensão e reflexão do estandarte com os órgãos reprodutivos permanecendo inclusos na quilha, sendo expostos somente durante o contato com o visitante.

Observou-se também que a abertura das flores de $C$. brasiliensis, dos indivíduos expostos aos primeiros raios solares parece ocorrer mais cedo, fato também observado por Carvalho e Oliveira (2003) em Senna sylvestris (Leguminoseae). Os estigmas dos botões florais já se encontram receptivos desde, aproximadamente, às $6 \mathrm{~h}$ precedentes ao início do processo de antese. Neste estádio as anteras ainda permanecem indeiscentes, só iniciando a liberação de pólen mais ou menos sincronicamente com o processo de abertura da flor. O estigma permanece receptivo até $24 \mathrm{~h}$ após a antese.

As flores ficam abertas ao longo de $14 \mathrm{~h}$ de um dia e no fim da tarde iniciam o processo de senescência floral, caracterizado pelo murchamento e alteração da coloração do estandarte. Quando ocorreu a fecundação, o cálice e o ovário são caducos, na ausência desta toda a flor eliminada. A longevidade das flores de $C$. brasiliensis é relativamente curta e, possivelmente pode está relacionada com polinizadores que realizam a polinização da flor em poucas ou em uma só visita, conforme foi observado por Ramirez et al. (1990). 
As Fabaceae em geral possuem antese de apenas um dia e diurna (Primack, 1985), no entanto, podem ser encontrados períodos variados de longevidade, como em flores de Mucuna sp. que apresenta longevidade de 7 dias (Agostini, 2004) e flores de Sophora tomentosa que caem com quatro ou cinco dias após a antese (Nogueira e Arruda, 2006).

O nectário nesta espécie encontra-se entre a base da coluna estaminal e do ovário. O néctar é produzido em quantidades pequenas desde a fase de pré-antese, sendo armazenado na câmara nectarífera formada pelo cálice. Essa estrutura também já foi encontrada na espécie Mucuna sp. (Agostini, 2004). O volume de néctar produzido varia de 1-6 $\mu 1$ e a média da concentração de açúcares, em equivalentes de sacarose, variou em torno de $44-60 \%$ (Figura 2).

As flores de C. brasiliensis possuem diversos atributos da morfologia floral que as enquadram na síndrome de melitofilia propostos por Faegri e van der Pijl (1979), tais como: muitas flores por inflorescências, odor intenso e adocicado, coloração roxa, antese diurna e zigomorfia que estão associados à atração dos agentes polinizadores. A concentração de açúcares no néctar (44-60\%) é também equivalente à amplitude (30-48\%) de outras espécies melitófilas proposto por Proctor et al. (1996). No entanto, Kiill et al. (2000) constatou que o beija-flor Phaethornis sp era um dos polinizadores desta espécie, embora não se enquadrasse no padrão ornitófilo.

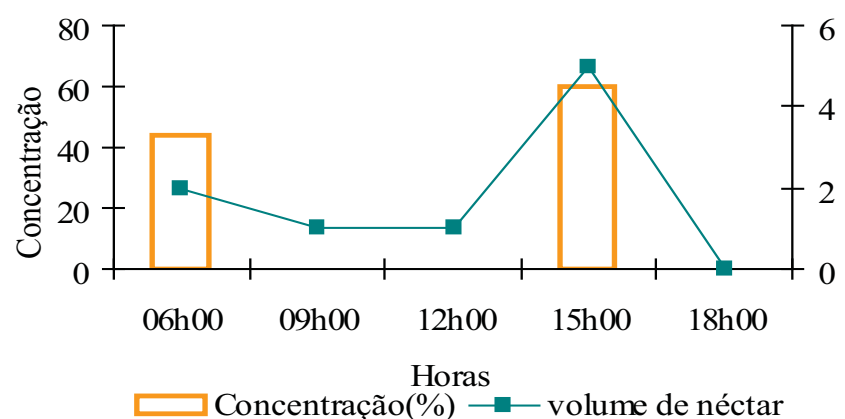

FIGURA 2: Concentração de açúcares (\%) e volume de néctar $\mu 1$ de flores de Canavalia brasiliensis Mart. ex Benth., em área de vegetação natural, Pocinhos - PB, no período de maio/2005 a novembro/2006.

Os maiores valores de concentração e volume de néctar foram encontrados no horário de $15 \mathrm{~h} 00$. Provavelmente, a produção de néctar e conseqüente aumento da concentração estejam associados a fatores climáticos como a temperatura e umidade, conforme já verificado por Baker e Baker (1982). Para C. brasiliensis o néctar é o recurso primário, podendo o pólen ser também forrageado. Kiill et al. (2000) afirmam que o néctar é o único recurso floral coletado em C. brasiliensis.

\section{Fenologia}

$\mathrm{Na}$ área estudada a espécie demonstrou padrão de floração anual, contínua, de longa duração de acordo com a classificação de Newstrom et al. (1994), com períodos de maior atividade fenológica de floração na estação seca (Figura 3). O fato de C. brasiliensis apresentar floração anual, disponibilizando recursos alimentares ao longo do ano a várias espécies de pássaros nectarívoros e de Anthophoridae, a torna uma espécie importante na manutenção do equilíbrio do ecossistema.

A frutificação começa logo após o início do período de floração e se estende até o início da floração seguinte. Na população estudada, observamos que esta espécie possui frutos o ano inteiro, quando se analisa a fase de frutos verdes e de frutos maduros. No período de maior atividade de espécies em floração, podemos observar alguns frutos secos que ainda não foram dispersos.

As fenofases de floração e frutificação foram classificadas como eventos não paramétricos. Conforme descrito na Tabela 1, o teste de correlação de Spearman mostrou que houve correlação negativa entre ambas as fenofases e a precipitação do mês e do mês anterior a este evento, confirmando assim, que tal fator abiótico não é o agente promotor para sua ocorrência.

TABELA 1: Teste da correlação de Spearman $(\mathrm{p}<0,05)$, em flores de Canavalia brasiliensis Mart. ex Benth., em área de vegetação natural, Pocinhos - PB, no período de maio/2005 a novembro/2006.

\begin{tabular}{|l|c|c|c|}
\hline \multirow{2}{*}{ Fenofases } & \multicolumn{3}{|c|}{ Precipitação Pluviométrica } \\
\cline { 2 - 4 } & $\mathbf{P}_{\mathbf{1}}$ & $\mathbf{P}_{\mathbf{2}}$ & $\mathbf{P}_{\mathbf{3}}$ \\
\hline Floração & $\mathrm{R}=-0,63$ & - & - \\
Frutificação & $\mathrm{R}=-0,63$ & $-0,61$ & - \\
\hline
\end{tabular}

$\mathrm{P}_{1}$ : Precipitação do mês do evento fenológico; $\mathrm{P}_{2}$ : Precipitação do mês anterior ao evento fenológico; $\mathrm{P}_{3}$ : Precipitação de dois meses anteriores ao evento fenológico; Ausência (-): indica que não houve correlação. 


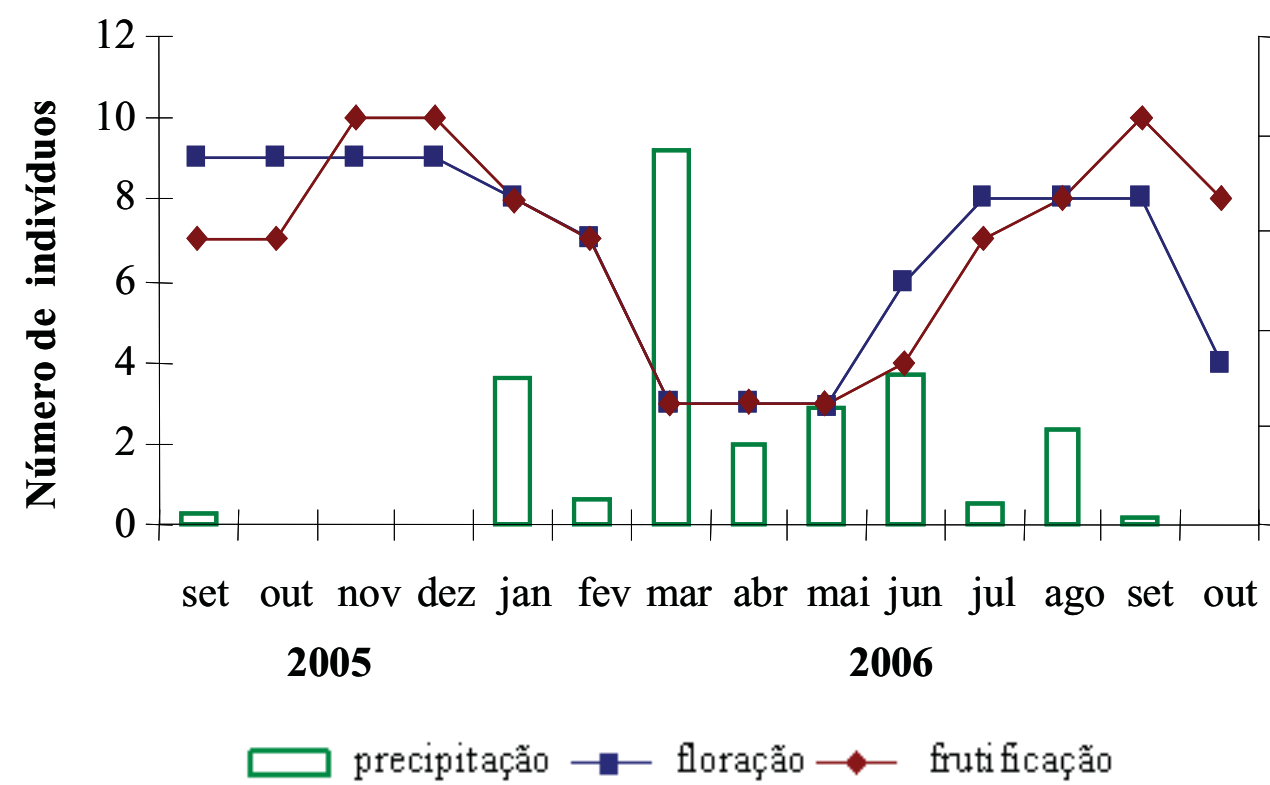

FIGURA 3: Número de plantas de Canavalia brasiliensis Mart. ex Benth. em floração e frutificação, em área de vegetação natural, Pocinhos - PB, no período de setembro/05 e outubro/06.

Verificamos com o estudo que ocorre uma diminuição na produção de flores e frutos nos meses próximos a primavera. A temperatura, a umidade relativa e o fotoperíodo podem influenciar a produção e o desenvolvimento de botões, flores e frutos (Marques e Oliveira, 2004). O período de floração é variado entre as espécies, em estudos realizados com Kiill e Drumond (2001) observando a G.sepium, e Agostini (2004) observando Mucuna sp. identificaram que as espécies têm pico de floração na estação seca, podendo a redução de umidade do solo e da atmosfera terem agido como um sinal para a floração da espécie, assim como foi verificado na tendência apresentada pela população de C. brasiliensis, no local desse estudo, a qual tem um aumento da atividade reprodutiva nos meses mais secos, no entanto, esta atividade reprodutiva pode ser estimulada pelo aumento da precipitação em meses que antecedem a floração.

Ipomoea asarifolia (Ders.) Roem. \& Schult. tem seu pico floração e frutificação ao longo da estação seca (Kiill e Ranga, 2003). Da mesma forma a espécie Mucuna sp. (Agostini, 2004). Nogueira e Arruda (2006) detectaram que na espécie Sophora tomentosa L. há diminuição da floração e frutificação próximas aos meses chuvosos. Já para as bromeliáceas dos gêneros Tillandsia
L., Vriesea Lindl., Aechmea Ruiz \& Pav., Billbergia Thunb. e Nidularium Lem., a floração coincide com a estação chuvosa (Machado e Semir, 2006).

\section{Visitantes}

Ao longo da floração as flores de C. brasiliensis foram visitadas por diversas espécies (Tabela 2). Cinco espécies de abelhas foram registradas (Xylocopa frontalis, X. suspecta, Xylocopa sp; Apis mellifera e Centris similis), representando $55,5 \%$ do total de visitantes, onde se destaca as abelhas do gênero Xylocopa como as mais freqüentes (Figura 4). Xylocopa frontalis $e$ $X$. suspecta realizaram as primeiras visitas entre $05 \mathrm{~h} 00 \mathrm{e}$ $05 \mathrm{~h} 30$, período em que as flores ainda estavam abrindo, mas já produzindo néctar. As visitas prolongaram-se até o final da tarde (17h40), quando cessava a produção de néctar. De uma forma geral, a maioria das abelhas Xylocopa frontalis, X. suspecta e Xylocopa sp. visitaram as flores de $C$. brasiliensis durante todo o período de observação (de maio de 2005 a novembro de 2006), sendo mais freqüente entre $07 \mathrm{~h} 00 \mathrm{~h}$ e $09 \mathrm{~h} 00$ e $15 \mathrm{~h} 00 \mathrm{e}$ $18 \mathrm{~h} 00$, fato que pode estar diretamente relacionado com a produção de néctar. 
TABELA 2: Visitantes florais, recompensa alimentar e eficácia da polinização em flores de Canavalia brasiliensis Mart. ex Benth., em área de vegetação natural, Pocinhos - PB, no período de maio/2005 a novembro/2006. Nt - néctar; $\mathrm{Pl} / \mathrm{Nt}$ - pólen/ néctar; $\mathrm{Pz}$ - polinizador; $\mathrm{Pd}$ - pilhador.

\begin{tabular}{l|c|c}
\hline \multicolumn{1}{c|}{ Visitantes } & $\begin{array}{c}\text { Recompensa } \\
\text { alimentar }\end{array}$ & $\begin{array}{c}\text { Eficácia da } \\
\text { polinização }\end{array}$ \\
\hline ABELHAS & & \\
Xylocopa suspecta & & $\mathrm{Pz}$ \\
Xylocopa frontalis & $\mathrm{Nt}$ & $\mathrm{Pz}$ \\
Xylocopa $\mathrm{sp}$ & $\mathrm{Nt}$ & $\mathrm{Pz}$ \\
Centris similis & $\mathrm{Pl} / \mathrm{Nt}$ & $\mathrm{Pd}$ \\
Apis mellifera & $\mathrm{N}$ & $\mathrm{Pd}$ \\
\hline AVES & & \\
Eupetomena macroura & $\mathrm{Nt}$ & $\mathrm{Pd}$ \\
Chlorostilbon aureoventris & $\mathrm{Nt}$ & $\mathrm{Pd}$ \\
Phaethornis ruber & $\mathrm{Nt}$ & $\mathrm{Pd}$ \\
Coereba flaveola & $\mathrm{Nt}$ & $\mathrm{Pd}$ \\
\hline
\end{tabular}

Com relação ao comportamento de visita, as abelhas apresentaram semelhanças entre si, sobrevoando as inflorescências e pousando sobre o estandarte, deslocando-a para baixo com suas pernas traseiras. Simultaneamente, empurram com a cabeça as alas e a quilha para cima e, posteriormente introduziam a língua na base dos elementos florais para alcançar o néctar.

Com esse comportamento de visita, os estames e o estigma, que ficam protegidos pelas quilhas e alas, são expostos rapidamente, tocando o tórax e a parte anterior do seu abdômen. Enquanto coleta o néctar, essa abelha movimenta as pernas medianas e traseiras sobre os estames em direção ao abdômen realizando a coleta do pólen e armazenando seus grãos em suas escopas, na parte ventral do abdômen. A abelha Centris similis coletou apenas néctar e devido o seu porte não permitiu a exposição das estruturas reprodutivas, sendo, portanto pilhadora de néctar (Figura 4).

Estas abelhas visitam as flores abertas durante o dia, com exceção de Apis mellifera, que preferencialmente visita flores com $24 \mathrm{~h}$ depois de abertas para coletarem pólen. Apis mellifera apresentou dois comportamentos, um para a coleta de pólen e outro para a coleta de néctar. No primeiro caso, $A$. mellifera pousava sobre as alas e a quilha e com auxílio das peças bucais e das pernas abriram-nas coletando o pólen, que era diretamente transferido para as pernas traseiras. Para a coleta de néctar esta espécie tinha o comportamento de pousar no estandarte sem acionar o mecanismo de exposição dos órgãos reprodutivos da flor, sendo considerada pilhadora de néctar.

Dentre as espécies de abelhas que visitam as flores de C. brasiliensis, Xylocopa frontalis foi considerada polinizadora efetiva, por possuir o maior número de características de um eficiente polinizador. Um polinizador eficiente é caracterizado por sua abundância, capacidade de transportar pólen sobre o corpo, fidelidade à espécie visitada (Lindsey, 1984) e capacidade de contatar o estigma e as anteras (Sugden, 1986).

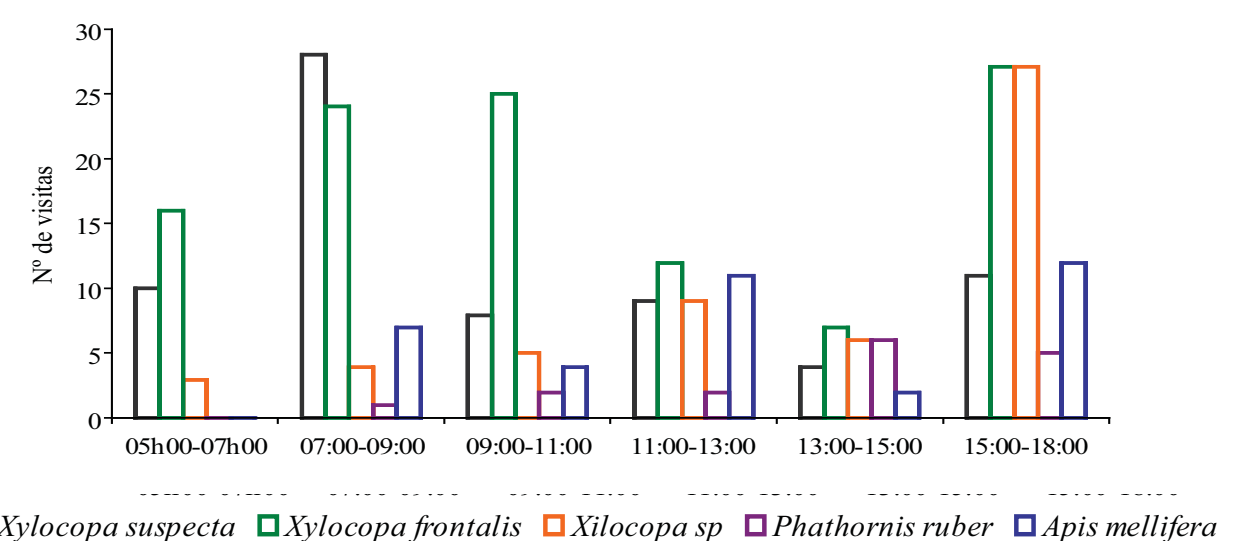

FIGURA 4: Freqüência de visitas de Canavalia brasiliensis Mart. ex Benth. em flores de Canavalia brasiliensis Mart. ex Benth., em área de vegetação natural, Pocinhos - PB, no período de maio/2005 a novembro/2006. 
Xylocopa frontalis possui uma alta freqüência de visitas durante toda a floração da planta, visitando várias flores por planta e várias plantas diferentes, coletando pólen com grande eficiência, e contatando também o estigma, podendo promover polinização cruzada. As abelhas do gênero Xylocopa se comportam como polinizadoras em algumas espécies de Fabaceae como Canavalia rosea (Gottsberger et al., 1988), Dioclea grandiflora (Guedes e Quirino, 2005) e Sophora tomentosa (Nogueira e Arruda, 2006).

A alta freqüência de visitas Xylocopa frontalis pode ser atribuída às pequenas quantidades de néctar produzidas por flor, levando o animal a visitar muitas flores, várias vezes, no intuito de suprir suas necessidades alimentares.

Os beija-flores Phaethornis ruber, Chlorostilbon aureoventris e Eupetomena macroura e o pássaro nectarívoro Coereba flaveola, restringem-se a pilhar o néctar, realizam visitas ilegítimas. As visitas dos beija-flores pela manhã eram rápidas e esporádicas, permanecendo na população de 3 a $5 \mathrm{seg}$, já no período da tarde a permanência aumentava, com média de $8 \mathrm{~min}$ por planta. Pousavam na inflorescência de $C$. brasiliensis, no pedúnculo ou em ramo próximo. A seguir, inclinavam a cabeça em direção à flor e inseriam o bico pilhando o néctar pela base das alas e quilha, sem com as estruturas reprodutivas da flor. Estas visitas mostram que os beija-flores são generalistas, e para manter a sua dieta alimentar, visitam flores com padrões melitófilos. No entanto, na família Fabaceae são conhecidas espécies ornitófilas (Agostini, 2004) e melitófilas (Kiill e Drumond 2001).

\section{Experimentos de polinização}

Os resultados obtidos nos diferentes experimentos de polinização estão agrupados na Tabela 3. Não se observa a formação de frutos apomíticos, bem como os botões florais submetidos à autopolinização não formaram frutos. Resultados semelhantes à espécie foram obtidos por Kill e Drumond (2001) com Gliricidia sepium. A autopolinização espontânea na espécie Cnidosculus juercifolius resultou em $4,3 \%$ dos frutos formados, revelando um baixo percentual de frutos formados, quando comparados à polinização natural (100\%); também no teste de apomixia não houve formação de frutos (Silva et al., 2006). Na espécie Spiranthera odoratissima não houve formação de frutos por autopolinização espontânea, indicando que a espécie necessita da ação de agentes polinizadores para a transferência de grãos de pólen das anteras para a superfície estigmática (Silva e Santos, 2008).

Foram encontrados frutos apenas nos experimentos de polinização cruzada e natural. Diante dos resultados, fica clara a importância dos polinizadores de $C$. brasiliensis, principalmente porque esta espécie é autoincompatível, dependendo inteiramente desses animais na dispersão de pólen entre os indivíduos, os quais garantem o sucesso reprodutivo da espécie.

O número de frutos formados em condições naturais foi baixo, podendo ser explicado pelo alto número de frutos abortados. Em Fabaceae a incidência de frutos abortados é alta como em duas espécies de Dahlstedtia (Teixeira et al., 2001) e em Mucuna sp. (Agostini, 2004).

TABELA 3: Experimentos de polinização em flores de Canavalia brasiliensis Mart. ex Benth., em área de vegetação natural, Pocinhos - PB, no período de maio/2005 a novembro/2006.

\begin{tabular}{l|c}
\multicolumn{1}{c|}{ Tratamentos } & Sucesso \% (Fl/Fr) \\
\hline Autopolinização espontânea & $0(30 / 0)$ \\
\hline Polinização cruzada & $10(30 / 3)$ \\
\hline Apomixia & $0(30 / 0)$ \\
\hline Polinização natural (controle) & $16,6(30 / 5)$ \\
\hline Eficácia do polinizador & \\
\hline Xylocopa frontalis & $19,92(30 / 6)$ \\
\hline Xylocopa suspecta & $10(30 / 3)$ \\
\hline Xylocopa sp & $3,3(30 / 1)$ \\
\hline
\end{tabular}

Fl: $n^{\circ}$ de flores; Fr: $n^{\circ}$ de frutos.

Baixas taxas de frutificação foram observadas em condições naturais, indicando que possivelmente houve falhas na polinização, decorrente provavelmente do pequeno número de visitas dos agentes polinizadores. Uma outra possibilidade de explicação para este fato é que a curta longevidade floral deixa as flores de $C$. brasiliensis expostas aos polinizadores por um período 
reduzido. Isso quer dizer que, a curta longevidade floral impede os polinizadores efetivos (Xylocopa frontalis) realizem uma maior quantidade de visitas em dias distintos, o que pode elevar os níveis de polinização para a espécie e, conseqüentemente, uma maior formação de frutos.

Os resultados provenientes desta pesquisa contribuíram para a ampliação dos conhecimentos a respeito das estratégias ecológicas de $C$. brasiliensis. Entretanto, a sua biologia reprodutiva e seu sistema de polinização ainda precisam ser mais bem estudados, visto que se trata de uma espécie pouco investigada cientificamente, apesar de sua ampla utilização na área de caatinga.

\section{Referências}

Ab'Saber, A. N. 1977. Os domínios morfoclimáticos da América do Sul. Primeira Aproximação. Geomorfologia, 52: 1-21.

Agostini, K. 2004. Ecologia da polinização de Mucuna sp nov. (Fabaceae) no litoral Norte de São Paulo, Brasil. Tese Doutorado, Universidade Estadual de Campinas, Brasil, 97pp.

Baker, H. G, Baker, I. 1982. Floral nectar sugar constituents relation to pollinator type. In: Jones, C. E. \& Little, R. J. (Eds). Handbook of experimental pollination biology. Van Nostrand Reinhold, New York, USA, p.117-141.

Barroso, G. M.; Peixoto, A. L.; Ichaso, C. L. F.; Guimarães, E. F.; Costa, C. G. 1991. Sistemática de Angiospermas do Brasil. v.1. Imprensa Universitária, Viçosa, UVF, 309pp.

Biondi, D.; Leal, L. Batista, A. C. 2007. Fenologia do florescimento e frutificação de espécies ativas dos Campos. Acta Scientiarum Biological Sciences, 29 (3): 269-276.

Carvalho, A. M.; Sodré Filho, J. 2000. Uso de adubos verdes como cobertura do solo. Boletim de Pesquisa - Embrapa Cerrados $\mathrm{N}^{\circ}$ 11, Empresa Brasileira de Pesquisa Agropecuária (EMBRAPA) Cerrados, Planaltina, Brasil, 20pp.

Carvalho, D. A.; Oliveira, P. E. 2003. Biologia reprodutiva e polinização de Senna sylvestris (Vell.) H.S. Irwin e Barneby (Leguminosae, Caesalpinioideae). Revista Brasileira de Botânica, 26 (3): 319-328.

Dafni, A. 1992. Pollination ecology: A practical approach. Oxford University Press, New York, USA, 250pp.

Eiten, G. 1983. Classificação da vegetação do Brasil. CNPq/ Coordenação Editorial, Brasília, Brasil, 65pp.

Faegri, K.; van der Pijl., L. 1979. The principles of pollination ecology. Pergamon Press, Oxford, UK, 239pp.

Franco, A. L. M. 1995. Ecologia da polinização e biologia reprodutiva de sete espécies de Phaseoleae (Fabaceae). Tese de Doutorado, Universidade Estadual de Campinas, Brasil, 123pp.

Gottsberger, G.; Camargo, J. M. F.; Gottsberger, I. S. 1988. A beepollinated tropical community: The beach dune vegetation of
Ilha de São Luís, Maranhão, Brazil. Botanische Jahrbücher für Systematik, 109 (4): 469-500.

Grantsau, R. 1989. Os beija-flores do Brasil: Uma chave de identificação para todas as formas de beija-flores do Brasil com a descrição de quatro novas formas. Editora Expressão e Cultura, Rio de Janeiro, Brasil, 315pp.

Guedes, R. S.; Quirino, Z. G. M. 2005. Biologia reprodutiva e visitantes de Dioclea grandiflora, Mart. ex. Benth. (Fabaceae), em área de Caatinga. Anais do $5^{\circ}$ Congresso Nacional de Botânica, Curitiba, Paraná, Brasil, p.10.

Inouye, D. W.; Favre, N. D.; Lanun, J. A.; Levine, D. M.; Meyers, J. B.; Roberts, M. S.; Tsao, F. C.; Wang, Y. Y. 1980. The effect of non-sugar nectar constituents on estimates of nectar energy content. Ecology, 61: 992-995.

Isidro, R.; Sales, F. J. M.; Cavada,B. S.; Grangeiro, T. B. R. A. M. 2001. Ação de lectina de sementes de Canavalia brasiliensis Mart. sobre o comportamento da saúva do nordeste (Atta opaciceps Borgmeier, 1939 ). Revista de la Facultad de Agronomia, 27: 7786.

Kiill, L. H. P.; Drumond, M. A. 2001. Biologia floral e sistema reprodutivo de Gliricidia sepium (Jacq.) Steud. (Fabaceae Papilionoidae) na região de Petrolina, Pernambuco. Revista Ciência Rural, 31 (4): 597-601.

Kiill, L. H. P.; Haji, F. N. P.; Lima, P. C. F. 2000. Visitantes florais de plantas invasoras de áreas com fruteiras irrigadas. Scientia Agrícola, 57 (3): 575-580.

Kill, L. H. P.; Ranga, N. T. 2003. Ecologia da polinização de Ipomoea asarifolia (Ders.) Roem. \& Schult. (Convolvulaceae) na região semi-árido de Pernambuco. Acta Botanica Brasilica, 17 (3): 335-362.

Leal, I. R.; Tabarelli, M.; Silva, J. M. 2003. Ecologia e Conservação da Caatinga. Ed. Universitária da UFPE, Recife, Brasil, 804pp.

Lima, P. J.; Heckendorff, W. D. 1985. Climatologia. In: Paraíba (Estado) Secretaria da Educação e Universidade Federal da Paraíba (Eds). Atlas geográfico do estado da Paraíba. Grafset, João Pessoa, Brasil, p.34-43.

Lindsey, A. H. 1984. Reproductive biology of Apiaceae. I. Floral visitors to Thaspium and Zizia and their importance in pollination. American Journal of Botany, 71 (3): 375-387.

Machado, C. G.; Semir, J. 2006. Fenologia da floração e biologia floral de bromeliáceas ornitófilas de uma área da mata atlântica do Sudeste Brasileiro. Revista Brasileira de Botânica, 29 (1): 163 174.

Machado, I. C.; Lopes, A. V. 2003. Recursos florais e sistemas de polinização e sexuais em Caatinga. In: Leal, I. R.; Tabarelli, M. \& Silva, J. M. (Eds). Ecologia e Conservação da Caatinga. Ed. Universitária da UFPE, Recife, Brasil, p.515-559.

Marques, M. C. M.; Oliveira, P. E. A. M. 2004. Fenologia de espécies do dossel e do sub-bosque de duas florestas de restinga na Ilha do Mel, sul do Brasil. Revista Brasileira de Botânica, 27 (4): 713-723.

Mendonça, M. P.; Lins, L. V. (Org.). 2000. Lista vermelha das espécies ameaçadas de extinção da flora de Minas Gerais. Fundação Biodiversitas, Fundação Zoo-Botânica de Belo Horizonte, Brasil, 160pp. 
Moreira, E. 1997. Atlas de geografia agrária da Paraíba. Editora Universitária - UFPB, João Pessoa, Brasil, 189pp.

Newstron, L. E.; Frankie, G. W.; Baker, H. G. 1994. A new classification for plant phenology based on flowering patterns in Lowland Tropical Rain Forest Trees at La Selva, Costa Rica. Biotropica, 26: 141-159.

Nogueira, E. M. L.; Arruda, V. L. V. 2006. Fenologia reprodutiva, polinização e sistema reprodutivo de Sophora tomentosa L. (Leguminosae - Papilionoideae) em restinga da praia da Joaquina, Florianópolis, sul do Brasil. Biotemas, 19 (2): 29-36.

Pedroni, F.; Sanchez, M.; Santos, F. A. M. 2002. Fenologia da copaíba (Copaifera langsdorffii Desf. - Leguminosae, Caesalpinioideae) em uma floresta semidecídua no sudeste do Brasil. Revista Brasileira de Botânica, 25 (1): 177-182.

Pereira, S. F. 2005. Caracterização dos efeitos biológicos das lectinas de Canavalia brasiliensis (ConBr) e de Canavalia ensiformes (Con $\mathrm{A})$ em preparações do sistema nervoso central e em células tumorais. Dissertação de Mestrado, Universidade Federal de Santa Catarina, Brasil, 112pp.

Primack, R. B. 1985. Longevity of individual flowers. Annual Review of Ecology and Systematics, 16: 15-37.

Proctor, M.; Yeo, P.; Lack, A. 1996. The natural history of pollination. Harper Collins Press, London, UK, 479pp.

Ramirez, I. M.; Gil, C.; Hokche O.; Seres, A.; Brito, Y. 1990. Biologia floral de uma comunidade arbustiva tropical en la Guayna Venezoelana. Annals of the Missouri Botanical Garden, 77: 383 397.

Rover Júnior, L. 1995. Construção e avaliação de biossensor potenciométrico para determinação de uréia, com eletrodo íon- seletivo a amônio, usando Canavalia brasiliensis como fonte enzimática. Dissertação de Mestrado, Universidade Estadual de Campinas, Brasil, 109pp.

Sampaio, E. V. S. B. 2002. Uso das plantas da caatinga. In. Sampaio, E. V. S. B. \& Giulietti, A. M. (Ed.). Vegetação \& flora da Caatinga. Associação Plantas do Nordeste APNE; Centro Nordestino de Informação sobre Plantas CNIP, Recife, Brasil, p.49-90.

Silva, C. S. P.; Santos, M. L. 2008. Comportamento fenológico no evento pós-queima e biologia reprodutiva de Spiranthera odoratissima A. St.-Hil. (Rutaceae). Revista Biotemas, 21 (1): 2939.

Silva, L. M. M.; Aguiar, I. B.; Viégas, R. A.; Mendonça., Z. F. C. 2006. Biologia reprodutiva de Cnidosculus juercifolius Pax \& K. Hoffm (Euphorbiaceae). Revista de Biologia e Ciências da Terra, 6 (2): 25-34.

Sugden, E. A. 1986. Anthecology and pollinator efficacy of Styrax officinale subsp. redivivum (Styracaceae). American Journal of Botany, 73 (6): 919-930.

Teixeira, S. P.; Prakash, N.; Ranga, N. T. 2001. Ovule and early seed development related to seed abortion in Dahlstedtia pinnata and D. pentaphylla (Leguminosae, Papilionoideae). Phytomorphology, 51: 61-70.

Wendt, T.; Canela, M. B. F.; Faria, A. P. G.; Rios, R. I. 2001. Reproductive biology and natural hybridization between two endemic species of Pitcairnia (Bromeliaceae). American Journal of Botany, 88: 1760-1767.

Zeisler, M. 1983. Ümber die abgreenzung der eigentlichen narberfläche mit hilfe von reaktionen. Beihefte zum Botanischer Zentralblatt, 58: 308 . 